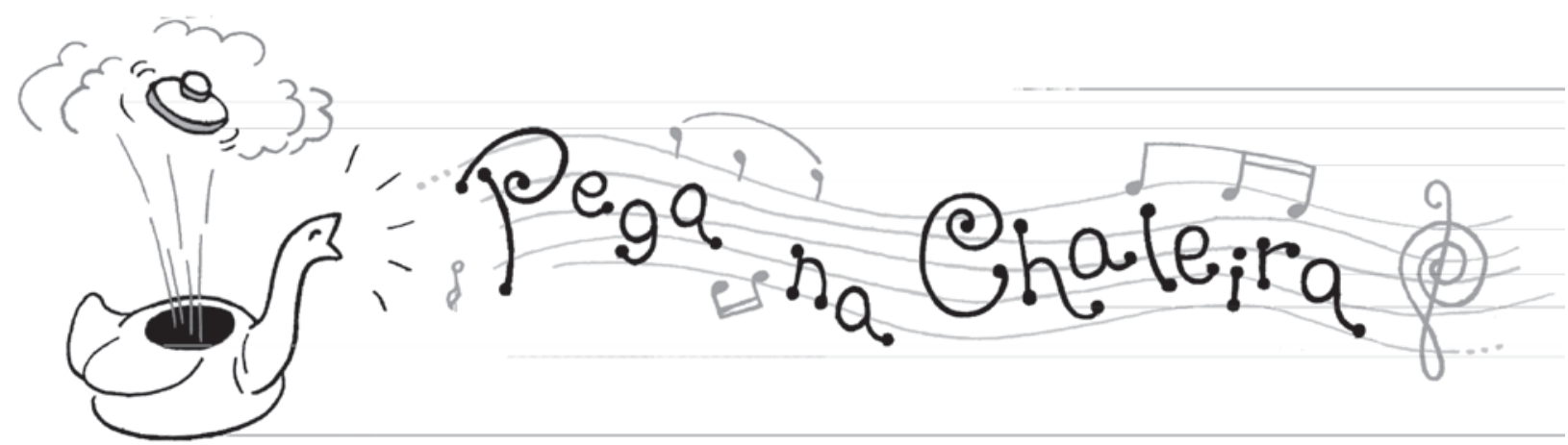

PEGA NA CHALEIRA - RESENHAS

\title{
Resenha sobre a tese de doutorado $O$ Violão na era do disco: interpretação e desleitura na arte de Juliam Bream de Sidney Molina Júnior
}

\author{
Luciano Hercílio Alves Souto (UNESP, São Paulo, SP) \\ Ihasouto@yahoo.com.br
}

Palaras-chave: violão na era do rádio; interpretação musical; Andres Segovia; Juliam Bream.

Review of the dissertation The guitar in the LPs era: interpretation and misreading in the art of Juliam Bream by Sidney Molina Júnior

Keywords: guitar in the radio era; musical interpretation; Andrés Segovia; Juliam Bream.

\section{1 - A Tese}

As práticas interpretativas em seu momento atual sofrem certo isolamento epistemológico em relação às demais áreas do conhecimento, ocasionando certa restrição do seu espaço próprio de reflexão. Em sua tese intitulada o violão na era do disco, MOLINA (2006, p.24) aponta para o problema ao se referir às práticas interpretativas como subsidiárias de outras áreas como Composição, Análise, Estética, Etnomusicologia, até mesmo da "subjetividade caprichosa das emoções dos intérpretes". Tal declaração desperta nossa reflexão para a importância do diálogo entre tal área e outras instâncias da produção do conhecimento, com vistas à conquista da autonomia necessária à investigação de seus próprios objetos de estudo, de maneira suficiente. $\mathrm{Na}$ medida em que disponibiliza material fonográfico de relevância sobre a produção musical violonistica e discute questões relacionadas à interpretação musical pelo viés da filosofia e da estética, o objeto desta resenha representa um importante canal de diálogo com as práticas interpretativas. A despeito de sua produção estar vinculada à área de comunicação e semiótica, a tese aqui resenhada fornece subsídios teóricos imprescindiveis à ampliação e ao aprofundamento das discussões interpretativas na área da performance. 0 violão na era do disco: interpretação e desleitura na arte de Juliam Bream trata da constituição e do estabelecimento do 
cânone ${ }^{1}$ do repertório violonístico, ressaltando a era dos LPs (1950-90) como marco central deste processo. A produção fonográfica de dois personagens principais é investigada pela tese: o Espanhol Andres Segovia (18931987) e o Inglês Juliam Bream (1933), cujas gravações são analisadas à luz de autores como Dahlhaus (1991), Adorno (1974), Lotman (1996), Said (1991) e Bloom (1993). Molina demonstra a ascensão e consolidação do repertório do violão clássico junto ao cenário internacional de concertos, em analogia à transformação conceitual do disco, partindo do "LP - Recital" até o "LP - Obra", por meio de um levantamento minucioso das gravações realizadas por tais violonistas, recuperando o contexto original de seus discos.

Dividida em duas partes de três capítulos cada, excluídos a coda e os apêndices, o trabalho se organiza da seguinte forma: o primeiro capítulo é dedicado à "Performance Musical como Desleitura" e se desenvolve a partir da temática relacionada à autenticidade interpretativa, empreendendo discussões sobre tópicos específicos das principais teorias da interpretação predominantes na segunda metade do séc. XX. 0 subtítulo "Performance e crítica" é introduzido com forte teor crítico, no momento em que o autor, ao comentar uma citação de Dahlhaus (1991) declara:

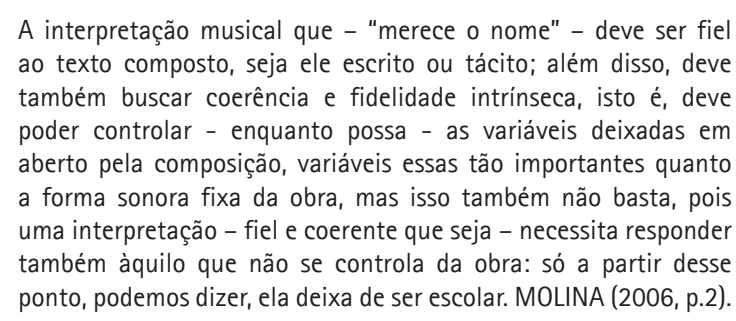

Tal declaração introduz de forma contundente a discussão sobre interpretação musical, perpassando os eixos: estilística e semântica versus estilística e retórica, termos estes introduzidos por Lotman, abrindo caminho para a tese da multiplicidade de interpretações. 0 capítulo inicial é encerrado com a proposição da desleitura bloomiana $^{2}$ para o contexto das autenticidades, que constituem o foco da discussão preliminar empreendida neste momento inicial.

0 segundo capítulo, "Um cânone a partir do som" traça um panorama histórico do desenvolvimento do disco no séc. $X X$, demonstrando o impacto do aprimoramento tecnológico da produção fonográfica sobre 0 desenvolvimento do disco enquanto projeto estético. Neste contexto, a produção de Segovia é identificada como o centro do cânone do repertório violonístico, considerando que suas gravações ocorreram entre 1927 e 1977, aliadas ao ressurgimento ${ }^{3}$ do violão em virtude dos empreendimentos de Torres e Tárrega, no final do séc. XIX. Desta forma, a conjunção de todos esses fatores propiciou as condições necessárias para que a formação do cânone do repertório do violão clássico acontecesse durante 0 séc. $X X$, em plena era do disco. Segundo Molina:
0 fato desse processo se constituir durante o séc. $X X$ traz uma importante diferença em relação às tradições dos outros instrumentos: a força das gravações não apenas apresenta obras, mas seleciona e consolida - para sempre - o próprio som do instrumento, cujo conceito não estava pronto antes desse momento. Por isso - e para além dos repertórios possiveis o cânone do violão na era do disco é, antes de tudo, o seu próprio som: sua voz, sua dicção, seus recursos expressivos, sua técnica, seus efeitos de timbre e percussão, seus silêncios. MOLINA (2006, p.49).

Tal declaração demonstra que o cânone do repertório violonístico constitui um fenômeno tardio, ocorrido em pleno séc. $X X$, se comparado ao cânone do repertório pianístico e orquestral que remontam o final do séc. XVIII. Portanto, essa tardividade "fez com que sua centralidade parecesse destinada, nesse momento inaugural, mais ao som dos intérpretes através das versões que eles fizeram das obras dos compositores do que às obras compostas, tomadas em si." MOLINA (2006, p.50).

Segundo o autor, a concepção atual sobre a formação do cânone pianístico é que se trata de uma seleção de obras compostas, partituras e edições, ao passo que o conhecimento do repertório executado por Segovia depende mais da escuta de suas próprias performances. Desta forma, suas interpretações parecem constituir o fundamento e não uma consequência de obras para violão compostas por Ponce, Tansman ou Torroba. MOLINA (2006, p.50).

Esta etapa da pesquisa, sobre a "Cena primária de instrução" versa sobre as origens poéticas de Juliam Bream. Utilizando como fundamentação teórica as desleituras de Freud e Derrida por Bloom, Molina procura afastar toda e qualquer espécie de idealização psicológico-biográfica, na intenção de abrir espaço para identificar na arte de Juliam Bream, a força da influência de Segovia. 0 terceiro capítulo é finalizado com a divisão da produção discográfica do violonista em três momentos, contendo duas fases cada um, contemplando um total de cinquenta discos. Tal empreendimento se deve em virtude da necessidade de apreensão da trajetória artística de sua carreira, desenvolvido na segunda parte da tese, sobre Uma desleitura do legado fonográfico de Juliam Bream.

Os próximos três capítulos tratam do desenvolvimento artístico propriamente dito da carreira de Juliam Bream. Desta forma, cada capítulo analisa separadamente cada uma das etapas que compõem tal desenvolvimento, contemplando o projeto estético de cada disco em particular, por meio da análise de aspectos como escolha do repertório, detalhamento técnico das gravações e utilização de instrumentos musicais específicos.

Um aspecto que julgamos pertinente ressaltar sobre a segunda parte da tese diz respeito ao estudo comparativo entre as discografias de Segóvia e Bream, empreendimento este realizado através do levantamento dos autores gravados por esses dois intérpretes e, no caso das obras gravadas por ambos, Molina apresenta comentários 
críticos sobre aspectos específicos de interpretação musical. Fundamentando-se na dialética da influência de Bloom, o autor demonstra como Segovia influencia a arte de Juliam Bream, tanto nos projetos dos discos quanto nas escolhas interpretativas.

0 quarto capítulo, "A arte de Juliam Bream" demonstra o desvio deste interprete em relação a Segovia, ressaltando três aspectos: o primeiro deles pode ser contemplado pela escolha do repertório, que atribui maior importância à musica inglesa. 0 segundo se refere à escolha dos instrumentos, no caso da utilização do alaúde, e na formação camerística. 0 terceiro aspecto está relacionado à vertente interpretativa, influenciada pela performance historicamente informada. No quinto capítulo, sobre Os LPs temáticos e $a$ instrução sonora, o autor analisa os projetos discográficos que envolvem a encomenda de obras inéditas a diversos compositores e verifica a constituição da maturidade artística de Bream, evidenciada pela conquista de uma sonoridade própria e de um estilo pessoal e particular de interpretação, diferenciando-se de Segovia.

0 sexto capítulo da tese parece constituir o clímax deste processo de influência entre intérpretes, permeado de angústia, na medida em que trata justamente do momento em que Bream enfrenta o repertório Segoviano de frente. De acordo com o autor, representativos desta fase clímax, sucedida de um momento posterior crepuscular são os discos: Juliam Bream plays Granados y Albéniz (1983) e La Guitarra Romântica (1991).

\section{2 - Reflexões críticas}

Em "um cânone a partir do som" (capítulo 2) Molina menciona um estudo intitulado Performing Music in the Age of Recording, de autoria de Robert Phillip (2004), no qual o autor demonstra o impacto dos primeiros registros fonográficos sobre a vida musical europeia e norte-americana quanto à padronização dos critérios para a performance, em relação ao período anterior às gravações no qual havia grande diversidade entre os padrões de interpretação musical. MOLINA (2006, p.3840). Desta forma, supomos que um processo semelhante possa ter ocorrido com a prática musical violonística, pois, na medida em que fixavam interpretações, as primeiras gravações podem ter sido reconhecidas entre os violonistas como referência para a execução musical, desencadeando uma prática de reprodução de interpretações que perdura até os dias de hoje.

Ao se referir às repetidas execuções de uma obra musical ao longo dos anos e ao caráter quase definitivo que ela pode adquirir em decorrência de uma espécie de elaboração formal adquirida por meio deste processo, HARNONCOURT declara que:

As numerosas interpretações de algum modo se copiam umas às outras, acabando por constituir uma forma legítima de execução que não pode mais ser ignorada em novas execuções [...] a tradição é considerada como uma espécie de purificação, de cristalização definitiva confirmada por longos anos de experiência." HARNONCOURT (1984, p.51).

Tal processo é criticado por DUPRAT $(2008$, p.8) pois, segundo o autor, a interpretação musical se transformou mundialmente numa grande fábrica de peças de reposição, sem qualquer preocupação com a pesquisa. Duprat vincula tal fato a uma universidade que já não é mais tão universal, à ânsia por carreira e a necessidade de enquadramento profissional, condenando a ausência de esforços direcionados à solução de problemas de andamento, dinâmica, ornamentação, ritmo e outros elementos na interpretação.

É exatamente sobre este aspecto que incide nossa crítica; considerando o atual estado do conhecimento sobre os conteúdos relacionados ao repertório do violão clássico, podemos afirmar que as interpretações recentes têm acrescentado muito pouco conteúdo ao repertório executado, no sentido da abordagem do repertório em questão, no que tange a soluções para questões de andamento, dinâmica, articulação, agógica, idiomatismo dentre outros aspectos. Mesmo com todos os estudos culturais relacionados à interpretação musical, empreendidos pelas mais diversas áreas do conhecimento tais como musicologia, sociologia, história, análise, estética e filosofia, as práticas interpretativas ainda carecem da percepção de que a interpretação de uma obra musical transcende a reprodução acrítica de execuções-modelo cristalizadas em gravações. A despeito da contribuição que os estudos culturais oferecem às questões da interpretação, retomamos o comentário sobre Dahlhaus em Molina: uma interpretação deixa de ser escolar quando é fiel ao texto, coerente e que responda também àquilo que não se controla da obra. MOLINA (2006, p.2). 


\section{Referências}

DUPRAT, Régis. Musicologia e Interpretação: teoria e prática. Revista eletrônica de divulgação científica, Faculdade de educação, Ciências e Letras Don Domenico.

GLOEDEN, Edelton. O Ressurgimento do Violão no Século XX: Miguel Llobet, Emílio Pujol e Andrés Segovia. Dissertação de Mestrado apresentada ao Departamento de Música da Escola de Comunicação e Artes, USP. São Paulo: 1996.

HARNONCOURT, Nikolaus. O Discurso dos sons. Rio de Janeiro: Jorge Zahar editor, 1998.

MOLINA JÚNIOR, Sidney. O violão na era do disco: interpretação e desleitura na arte de Juliam Bream. Tese de Doutorado defendida junto ao Programa de Estudos Pós-graduados em Comunicação e Semiótica da Pontifícia Universidade Católica de São Paulo, PUC-SP. São Paulo, 2006. . Performance Musical como Desleitura. ANPPOM, décimo quinto congresso / 2005.

\section{Leitura recomendada}

DAHLHAUS, Carl. Estética Musical. Tradução de Artur Mourão. Lisboa: Edições 70, 1991.

LOTMAN, Iuri M. La Semiosfera I. Semiótica de la cultura y Del texto.Tradução de Desiderio Navarro. Madrid: Ediciones Cátedra, 1996.

\section{Notas}

1 O cânone, palavra religiosa em suas origens, tornou-se uma escolha entre textos que lutam uns com os outros pela sobrevivência, quer se interprete a escolha como sendo feita por grupos sociais dominantes, instituições de educação, tradições de crítica, ou, como eu faço, por autores que vieram depois e se sentem escolhidos por figuras ancestrais. (BLOOM, Harold. O Cânone ocidental. Tradução de Marcos Santarrita. Rio de Janeiro: editora objetiva, 1994, p.27-28, In: Molina, 2006).

2 "A tetralogia da influência de Harold Bloom compreende os livros: A angustia da influência (1973), Um mapa da desleitura (1975), Cabala e crítica (1975) e Poesia e Repressão (1976)." (In: MOLINA, Performance Musical como Desleitura. ANPPOM-décimo quinto congresso-2005).

3 O termo "ressurgimento do violão" é utilizado por Edelton Gloeden em sua tese de Doutorado intitulada O Ressurgimento do Violão no Século XX: Miguel Llobet, Emílio Pujol e Andres Segovia, (São Paulo: Departamento de Música da Escola de Comunicação e Artes, USP. 1996).

Luciano Souto é Doutorando e Mestre em performance pelo Instituto de Artes da UNESP-SP, sob orientação da Prof. (a) Dr.(a) Gisela Gomes Pupo Nogueira. Atuou como professor assistente em caráter temporário na UEM - Universidade Estadual de Maringá-PR, entre 2009 e 2010, e como professor de violão na Associação Cultural Casa de Música de Ouro Branco durante os anos letivos de 1998 a 2003. Trabalha principalmente com os seguintes temas: Violão, Teoria e Prática da Performance, História da Música e música de câmara. Como solista de violão já se apresentou nos principais teatros e casas de cultura do país. 